\title{
ASSESSING THE INTEGRATION AND AUTOMATION OF ENERGY SYSTEMS IN NIGERIA
}

\author{
ADESHINA S. OLAGOKE, ALIYU B. DAHIRU \& AKEEM SALAWU \\ Computer Engineering Technology Department, Federal Polytechnic Mubi, Adamawa State Nigeria.
}

\begin{abstract}
Development of a country is totally based on the availability of sustainable electrical power. Due to epileptic power supply in Nigeria, generation, transmission, distribution, and usage of energy are to be optimized for proper conservation of energy. Nigerian electricity is mainly generated from different sources like hydro power plants, thermal power plants, and gas generating plants. Presently, the epileptic power supply and longtime fault detection during distribution is a very serious problem. Also vandalism of transmission lines, gas pipe lines to generating stations and shortages are common in Nigerian electrical distribution systems. It is therefore paramount to implement a method for power distribution automation. This paper discusses ways to modernize the present systems using supervisory control and data acquisition (SCADA) for automatic control of distribution systems. However, Nigerian power systems use manual tap changer which increases and encourages power outage with less safety to the system. Therefore, this paper suggests automatic tap changer which maintains the voltage of the system and thus reduces manpower.

Keywords: automation, conservation, distribution, manpower, optimized, power system, SCADA, tap changer, vandalism.
\end{abstract}

\section{INTRODUCTION}

A power system is an arrangement or set of devices that involves generation, transmission and distribution of power. This involves the physical and technical arrangement of these devices. The protection of the devices in a power system is done through monitoring and control devices referred to as the instrumentation and control system (I\&C).

Automation of power system in an electrical power network is a key area that requires careful investigation. A data acquisition system as one of the major aspects of power system automation plays a major role in power system automation. In power system automation, a data acquisition system can be carried out through the normal system method or a computerized system automation which is the most efficient one. A data acquisition system through computerized system automation helps the system and controller in terms of metering and monitoring of values so as to achieve full-scale automation and control of the power system. The data obtained are used to monitor the condition and status of power system by the personnel that supervises the system. The real time information can be remotely accessed on a computer graphical display through the network or locally on a laptop computer 'front panel display.

In an automated Power System, the various devices or equipment connected to the network are to be managed, controlled and even protected. The real time information can be obtained directly from the system either locally or remotely through control applications. However, power system automation is generally based on local intelligence, data flow with supervisory control and monitoring.

The three general classes of computerized data acquisition in a power system automation for metering and monitoring are data collection, metering \& monitoring. The data collection system obtains the data from the power system network by monitoring the current and potential transformers through the digital power monitor. The digital power monitor consists of a 
micro controller with the in-built like memory storage, analog to digital converter and other circuits. The microcontroller works in such a way that the digital power monitor stores the information in the memory storage and the logical and arithmetic calculations are done to update the parameters and to determine the different power parameters like WH, VAR, VA in kilo and, the power factor (PF) etc. The obtained parameters of the power system network and the determined power data can be monitored and controlled on the display panel of the digital power monitor. The parameters is then sent to the computer system using any available communication standards like serial communication RS 485 and 232 for different numbers of power monitors using the data converter.

Smooth operation and power distribution system maintenance is difficult for systems without topological information, latest health information of the equipment like distribution transformers and feeders pillars, historical archive of operation etc. for smooth operational planning and improved methodology for early or quick fault detection, isolation and restoration, hence there is a need for efficient tools to be installed. Presently, operational strategies like fault detection, isolation and service restoration takes a longer period making the power supply interruption to be delayed for a longer period of time [1], [2], and [3]. The substation was already tried to design and automate using the latest tools PLC and SCADA (supervisory control and data acquisition) to overcome the problems that arise in a power station [4], [5], and [6]. It is too late to modernize these distribution networks without these advanced automation tools. The present work is to integrate complete operations of the electrical substation with SCADA installed in a computer.

\section{LITERATURE REVIEW}

The history of Nigeria electricity generation begins with a few kilowatts that were generated in Lagos which was used by the colonial power in 1898. An act was enacted in 1951 that brought about the establishment of Electricity Corporation of Nigeria (ECN). Another authority was set up in 1962 to create a hydroelectricity generating station named 'Niger Dams Authority'. In 1972, Niger Dams Authority was combined with ECN to establish the National Electric Power Authority (NEPA). All the effort of the government to boost the electricity supply to meet the electricity need of its populace was below expectations. Hence, a new policy was invoked in the year 2001 named 'National Electric Power Policy (NEPP)' to bring about reforms in the power sector. NEPP brought about privatization of the power sector which was delayed but later implemented in the year 2005 .

The privatization process of the power sector was originally named Electric Power Sector Reform (EPSR) which later metamorphosed to Power Holding Company of Nigeria (PHCN). The act converting NEPA to Power Holding Company of Nigeria was enacted by 2005 and the PHCN was divided into three subsectors; Generation, Transmission and Distribution [7]. In the newly created Power sub-sectors, there are six power-generating companies called 'GENCOs', one transmission company and 11 distribution companies (DISCOs). These eighteen companies were charged with the task of electrical power generation, transmission, and distribution in the country [8].

The Nigeria electricity generating plants as shown in Table 1 are made up of four hydro power plants and six thermal generating stations with $10942 \mathrm{MW}$ total installed capacity but their total output have never gone beyond $3000 \mathrm{MW}$. The transmission of the generated electricity is done through the transmission lines, the lines operate in three phases: alternating current (AC), single-phase AC current and high-voltage direct current. However, because of the reduction in transmission losses, it is transmitted in kilo volts amperes (110 KVA or 330 KVA) as shown in Fig. 1 [9]. 
Table 1: Nigeria current power plants and their location [11].

\begin{tabular}{|c|c|c|c|}
\hline Power station & Location & $\begin{array}{l}\text { Installed capacity } \\
\text { (MW) }\end{array}$ & $\begin{array}{l}\text { Year } \\
\text { completed }\end{array}$ \\
\hline AES Barge & Egbin & 270 & 2001 \\
\hline Aba & Aba, Abia State & 140 & 2012 \\
\hline Afam IV-V & Afam, Rivers State & 726 & 1982 \\
\hline Afam VI & Afam, Rivers State & 624 & 2009 \\
\hline Alaoji (NIPP) & Abia State & 1074 & 2013 \\
\hline Calabar (NIPP) & Cross River State & 561 & 2014 \\
\hline Egbema (NIPP) & Imo State & 338 & 2013 \\
\hline Egbin & Egbin & 1320 & 1986 \\
\hline Geregu 1 & Geregu, Kogi State & 414 & 2007 \\
\hline Geregu 11 (NIPP) & Geregu, Kogi State & 434 & 2013 \\
\hline Ibom (NIPP) & Ikot Abasi & 190 & 2009 \\
\hline Ihorbor (NIPP) & Benin City & 450 & 2013 \\
\hline Okpai & Okpai & 480 & 2005 \\
\hline Olorunsogo & Olorunsogo & 336 & 2007 \\
\hline Olorunsogo II & Olorunsogo & 675 & 2012 \\
\hline Omoku & Omoku & 150 & 2005 \\
\hline Omoku 11 (NIPP) & Omoku & 225 & 2013 \\
\hline Omotosho 1 & Omotosho & 336 & 2005 \\
\hline Omotosho 11 (NIPP) & Omotosho & 450 & 2012 \\
\hline Sapele & Sapele & 1020 & 1981 \\
\hline Sapele (NIPP) & Sapele & 450 & 2012 \\
\hline Ughelli & Delta State & 900 & 1990 \\
\hline Itobe & Kogi State & 1200 & 2015-2018 \\
\hline Kainji & Niger State & 800 & 1968 \\
\hline Jebba & Niger State & 540 & 1985 \\
\hline Shiroro & Kaduna State & 600 & 1990 \\
\hline Zamfara & Zamfara State & 100 & 2012 \\
\hline Kano & Kano State & 100 & 2015 \\
\hline Kiri & Benue State & 35 & 2016 \\
\hline Mambilla & Taraba State & 3050 & 2018 \\
\hline
\end{tabular}

Current capacity=13,603 MW, Under-construction=4,385 MW, Total=17,988.

Source: National Control Centre, Osogbo

The distribution of electricity is a task given to Electricity Distribution Companies (Dis$\cos$ ) which provide the electricity supply value chain. Discos serve as the middle man between customers and the transmission companies. They are affected with problem of high cost production and low quality of service. The high voltage (132 KV) supplied by the 


\section{ELECTRIC POWER TRANSMISSION AND DISTRIBUTION LOSSES (\% OF OUTPUT)}

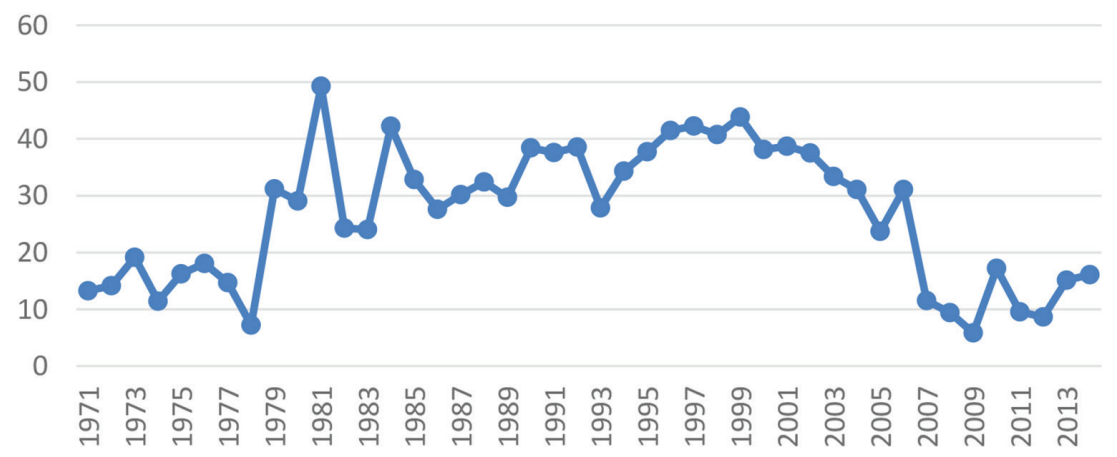

Figure 1: Electric power transmission and distribution losses in Nigeria [9].

Transmission station will be a step down by the Discos to a low voltage depending on the needs or voltage requirement of the final user. Electricity that is used in most residential homes is distributed at a voltage level of $0.415 \mathrm{kV}$. Discos are also charged with responsibility of marketing and sales of electricity to the customers. Table 2 shows the various Power Distribution Companies (Discos) and their covered states [10].

Nigeria electricity distribution companies are facing a lot of losses ranging from technical to non-technical losses. Technical losses include electrical losses due to resistance of the cable to the flow of current, electricity transmission equipment vandalism and theft, damage of equipment and infrastructure due to over voltage and electric spark, and equipment maintenance repair. Non-Technical losses are described as commercial and collection losses which arise from electricity theft, poor billing method, unmetered customers, inaccurate customers records and unaccounted for energy supplied or sold, while losses arising from inability to

Table 2: Electricity distribution companies and their covered areas in Nigeria [12].

Electricity Distribution Company

(Disco)

States Covered

Abuja Distribution Company

Benin Distribution Company

FCT, Niger, Nassarawa, Kogi

Enugu Distribution Company

Eko Distribution Company

Edo, Delta, Ekiti, Ondo

Imo, Anambra, Ebonyi, Abia, Enugu

Lagos State (Victoria Island, Lekki, Lagos Island,

Apapa, Epe, Ikoyi, etc.)

Port Harcourt Distribution Company

Ibadan Distribution Company

Rivers, Bayelsa, Cross Rivers, Akwa Ibom

Ikeja Distribution Company

Oyo, Ogun, Osun, Kwara

Lagos State (Ikeja, Surulere, Ikorodu, etc.)

Jos Distribution Company

Kano Distribution Company

Plateau, Bauchi, Benue, Gombe

Kaduna Distribution Company

Kano, Jigawa and Katsina

Kaduna, Sokoto, Kebbi and Zamfara

Yola Distribution Company

Adamawa, Borno, Taraba and Yobe 
collect revenue for energy billed to customers are referred to as collection losses. Discos faced a lot operational challenges that really affect their day to day activities and quality of service delivery to their customers. Some of the challenges are insufficient energy supply from generation grid; worn-out networks; poor maintenance tools; insufficient and poorly trained manpower; poor record keeping, workers safety and environmental issues; and absence of long-term capital to invest in Electricity distribution.

\section{POWER AUTOMATION}

Relay is one of the components used in analog circuit to bring operational automation in those days. Today, however, computer-based PROGRAMMABLE LOGIC is employed in most circuit operational automation which is made possible by the invention of the transistor, integrated circuits, microcontrollers and microprocessors. In electrical energy system, automation is mostly applicable at the substations and distribution levels. From the generation station, electrical energy is usually transmitted to the substation. At this section of the energy system, sophisticated equipment has been developed that enhances substation automation; this equipment is generally referred to as Intelligent Electronic Device (IED), which is made up of logic controllers that are programmable, ports that support automatic data execution and transmission control. The distribution level is the second level of automation, which receives power from the transmission line. Distribution level automation can be implemented in different phases from feeder pillars, electric power consumer devices and the total loads connected to the grid.

Transmission line is the medium through which electricity is been sent from the generating station to the distribution companies. Generally, the level of fault occurrence at the transmission level is less common than that of the distribution levels [13]. The complexity of the distribution network brought about a lot of failures not only from the distribution companies but also the consumers. For this reason, power distribution automation will bring about availability of power. According to the IEEE, 'a system that allows electric utility to be remotely monitored, coordinate and operate the distribution components, in a real-time mode from remote locations is referred as the distribution automation system [14]'. In Nigeria, the primary distribution sector is subdivided into two, namely, large consumers (no transformation provided) and less consumers (Secondary distribution).

SCADA provides remote operation control and monitoring for automation systems using communication technology. SCADA can be applied in areas of power generation, transmission, and distribution, wind power generation, industrial process and control, traffic signal, industries, and communication network. After collecting data from the system, a command is sent by the SCADA accordingly to monitor and control the system. Digital or analog sensors and control relays are used to gather information about individual equipment in the system through the communication Network. The data collected from the system is supervised at a station where the SCADA server is located to monitor equipment and issue control signal automatically or control from the human operator [15]. The Nigeria electricity network substation $(132 / 33 \mathrm{kV}$ and $33 / 11 \mathrm{kV})$ can be controlled using the SCADA system. The SCADA central control room manages the electricity network by coordinating with the central load dispatch center or at the request of human operators [16]. The components of a SCADA system are:

1. Analog or digital Sensors Remote telemetry units (RTU)

2. SCADA master units 
3. Communications network

4. Remote Communication Server (RCS)

The routine or steps performed by the SCADA to manage the overall automation of an electrical power system are:

1. The equipment at the substation is to be connected to Remote Telemetry Unit (RTU) through the RTU card using wire so that when any of the Substation is operated whether manually or remotely, the RTU collates the operational information from the database of the system using the microwave link which then later moved to the Remote Communication Server (RCS). For collection of the operational information, the RTU card of the Substation is connected to the circuit breaker and other switchgears of that substation. The RCS serve as final destination collected information from the substation and it is done through the modem. Figure 2 shows the block representation of RTU.

2. The collated data from all substation is sent to the nearby base station through the cable or a radio link. The electricity network of Nigeria can be designed to be controlled automatically by installing the RTUs at the eleven distribution stations. The eleven RTU at each substation collates the operational information of the equipment at their respective databases and send it to the RCS. Each base station is equipped with a microwave transceiver to receive data from the RTU at each substation through Ultra high frequency (UHF).

The microwave transceiver at the base stations forms a communication ring through which data is been transferred to the master station. Figure 3 demonstrate the linkage between the microwave transceiver communication ring and the master station.

3. All information collected from any of the substation regarding the operation of the switch gear is stored in the RCS of the master station. The master station is connected through the microwave receiving data through the antenna and later data are processed by RCS according to the status, which is then sent to the application server and stored in the database. Each SCADA master station comprises a server and workstation computers that are networked. The workstation PC at the substation is charged with remote operation of the substation based on the circuit breaker operation. The line diagram describes the status of circuit breakers of any substation. The single line diagram visualizes and indicates the operation of circuit breaker, active line, system voltage, frequency and power factor [17], [18].

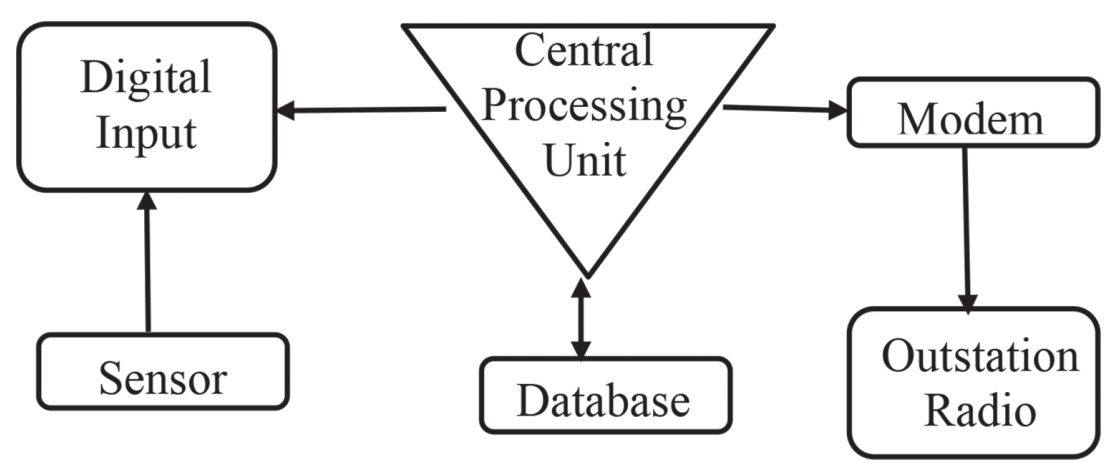

Figure 2: Block representation of RTU. 


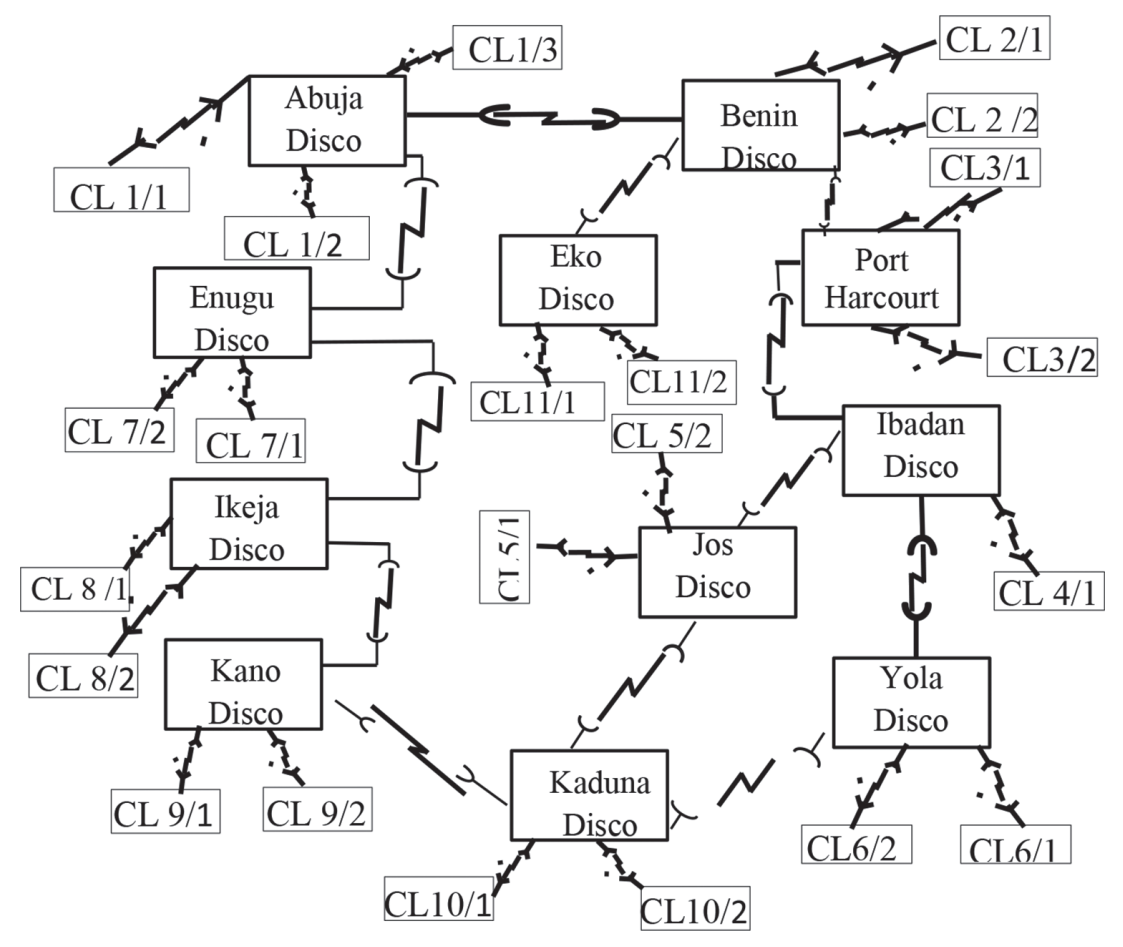

Figure 3: Microwave Communication link between the distribution stations.

\section{ELECTRICAL NETWORK AUTOMATED SYSTEM OPERATION}

An automated Electrical Network system can be made to operate on three modes; these are:

1. Manual mode

2. Auto mode and

3. Time bound mode

The manual mode is where the main station is being powered ON and OFF through two different push buttons. This mode is the archaic conventional mode where the substations can be switched ON only if the main station is switched ON. The feeders can be switched ON only if the corresponding substation is switched on. The whole substations and the sub feeders have their own ON and OFF push buttons. This is the mode Nigeria power network is being operated.

The automatic mode is the next mode, which in normal conditions acts like manual mode. But when the 'Auto' switch (toggle) is switched ON the logic acts in a different way. If any of the sub feeders are switched OFF in the automatic mode, it gets OFF first but after a minor delay will restart again itself automatically.

Lastly, there is the 'time bound' mode. This mode is controlled through SCADA. The time bound mode is where the operator can decide the hours in which the power can be distributed and hold. That is, if the operator sets a time between $2 \mathrm{pm}$ to $4 \mathrm{pm}$, the sub feeder gets OFF from $2 \mathrm{pm}$ to $4 \mathrm{pm}$ and switches $\mathrm{ON}$ automatically after the time is over. The time delay and the range of operation can be set through SCADA. This mode is useful for load shedding. 
The following intelligent electronic devices are required for an automated SCADA controlled distribution substation as shown in Fig. 5, they are:

1. Potential transformers (PT)

2. Current transformers (CT)

3. Main transformers

4. Disconnecting switches (DS)

5. Circuit breakers (CB)

The control and monitoring of the overall system along with the managerial tasks are performed by HMI (Human-Machine Interface) or an HCI (Human-Computer Interface) with the help of the SCADA system. Generally 132, 33 and $11 \mathrm{kV}$ circuit breakers are operated remotely by the control and monitoring of an electrical power Network with overall

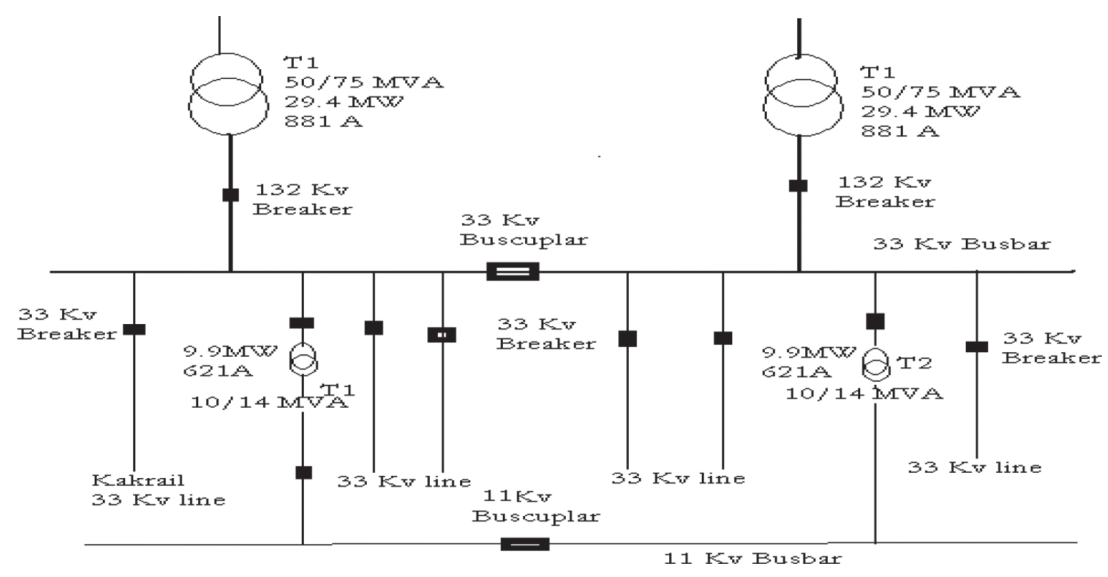

Figure 4: Line Diagram of a substation.

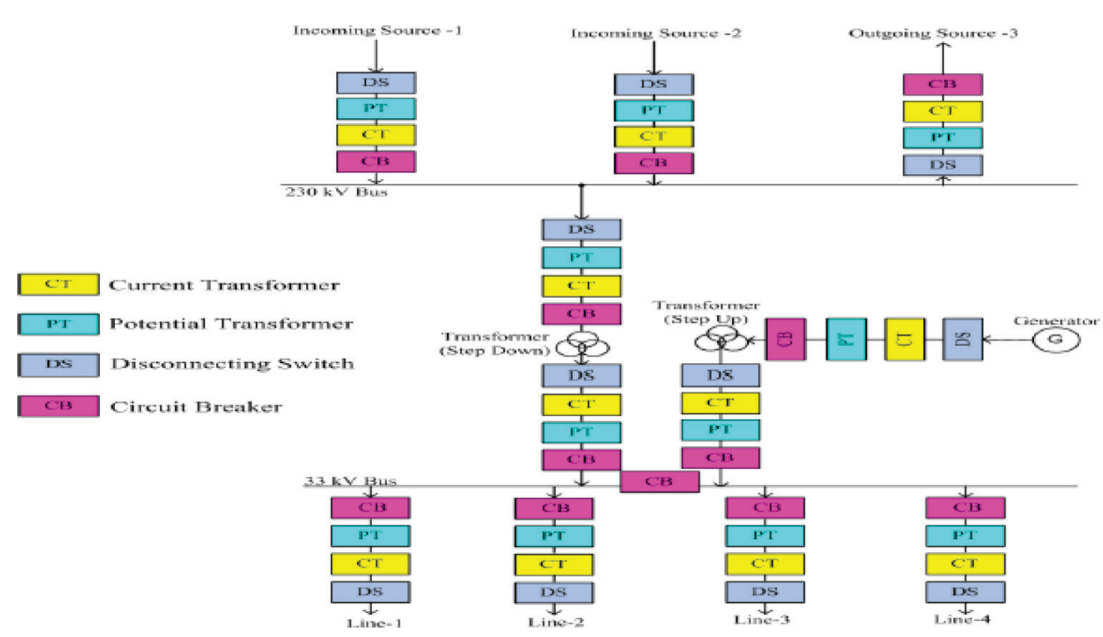

Figure 5: Block diagram of automated distribution substation. 
managerial processes can be perform with the help SCADA program whether through HMI or HCI. Generally, high voltage circuit breakers are remotely controlled using SCADA system as shown in Fig. 4. The procedure or routine commands to be followed in operating circuit breaker are stated below:

1. The control of any particular circuit breaker is done on the application server

2. Remote control is allowed.

3. The breaker is marked as updated.

4. The RTU card connects to each circuit breaker.

5. Remote control authority for the action is established.

6. Breaker is controlled from application server not from any other workstation.

7. Interlocking of breaker is very important and it must be done in proper sequence.

If any of the above is not met, a message box explains the present status of the circuit breaker. An alarm will indicate that there is a command sequence error. The error can be seen either in message box or in the event list.

\section{CONCLUSION}

The presented system for automation of electrical power distribution using SCADA eliminates most of the problems encountered in the Nigeria electricity network if not all. The method ensures safest and fastest transmission and distribution of power. Automatic restoration of power reduces time consumption and total outage time of feeders. The automatic tap changer maintains the voltage of whole system normally. The automation of the electrical power distribution system represents the easiest platform for the operator in this field. It gives a clear picture of the overall status of the system because of the record keeping of the system operation. The daily load demand required can be determined easily since the status of the overall system network can be understood within few seconds. The application of SCADA to the Nigeria electricity network can simplify its management with minimum human assistance. This study shows clearly that overall system performance, reliability, stability and control of the Nigeria electricity network can be improved if SCADA is employed. The manual operation that is been used at present requires huge manpower which increases the overall cost and allows corruption and mismanagement. Moreover, during system failures or occurrences of sudden power interruptions, quick decisions can be made when a SCADA system is employed. For efficient operation, easy control and proper monitoring of the Nigeria power grid system, it is important to engage the use of a SCADA system.

\section{REFERENCES}

[1] Gupta, R.P. \& Varma, R.K., Power Distribution Automation: Present Status, University of Western Ontario, Canada, 2012. https://doi.org/10.2316/journal.203.2007.2.203-3479

[2] John McDonald, D., Wojszczyk, B., Flynn, B. \& Voloh, I., "Distribution Systems, Substations, and Integration of Distributed Generation", Encyclopedia of sustainability science and technology, 2015. https://doi.org/10.1007/978-1-4419-0851-3_761

[3] Bassett, B., Clinard, K., Grainger, J., Purucker, S. \& Ward, D., "Tutorial Course: Distribution Automation," IEEE Tutorial Publ. 88EH0280-8-PWR, 1988.

[4] Chan, F.C., "Electric Power Distribution Systems", Encyclopedia of life support systems (EOLSS), Vol. 3. 
[5] Wilson, T., "PLC Based Substation Automation and SCADA Systems and Selecting a Control System Indicator.” Western electric power Institute, 1999.

[6] A White Paper from InduSoft, SCADA Systems Automate Electrical Distribution, PC-based supervisory control and data acquisition systems increase uptime, cut costs and improve utilization. Retrieved from Indusoft website: http://www.indusoft.com. (accessed 20th May, 2018).

[7] Emodi, V.N., Yusuf, S.D. \& Boo, K.J., The necessity of the development of standards for renewable energy technologies in Nigeria. Smart Grid and Renewable Energy, 5(11), pp. 259-274, 2014. https://doi.org/10.4236/sgre.2014.511024

[8] The Nigeria Electricity Grid Network available online at: www.geni.org. (accessed on 6th April, 2018).

[9] Oseni, M., An analysis of the power sector performance in Nigeria. Renewable and Sustainable Energy Reviews, 15(9), pp. 4765-4774, 2011. https://doi.org/10.1016/j. rser.2011.07.075

[10] Electric power transmission and distribution losses in Nigeria: World Bank.

[11] Nigeria Current Power plants and their location: National Control Centre, Oshogbo, 2017.

[12] Odion, O., "Electricity Distribution Companies - The Challenges and Way Forward", By Odion Omonfoman. Premium times. Retrieved from www.premiumtimes.com/articles/odionomonfoman-on- electricity distribution companies /116271, 2015 (accessed 20th April, 2018).

[13] Sheng, S., Xian zhong, D. \& Chan, W., "Probability Distribution of Fault in Distribution System", Power Systems, IEEE Transactions on, August 2008.

[14] McKenzie, I., Electrical Technology, 7th edn., Tada McGraw-Hill Publishing Company Limited, 1993.

[15] Floyed, T., Electronic Devices, 4th edn., Prentice Hall International, Inc, 1996.

[16] Glover, J., Sharma, M. \& Overbye, T. Power System Analaysis and Design, 4th edn., Thomson Learning, Thomson Corporation, USA, pp. 60-85, 120-150, 210-300, 2008.

[17] Grainger, J. \& Stevenson, W., Power System Analysis, International edition, McGraw-hill book co., Singapore, pp. 105-180, 350-400, 512-516, 1994.

[18] Stevenson, W.D., Elements of Power System Analysis, International Edition, MacGraw Hill Book Co., Singapore, pp. 45-60, 90-120, 220-250, 1994. 